\title{
Effects of early experiences on one-trial avoidance conditioning '
}

\author{
ROBERT ADER, UNIVERSITY OF ROCHESTER SCHOOL. OF MEDICINE AND DENTISTRY \\ ARLENE SCHAEFER, UNIVERSITY OF ROCHESTER
}

Female rats were either handled, shocked, or unmanipulated during the pre- or immediate postweaning period. At maturity they were observed in a one-trial avoidance situation. On the single conditioning trial, they were shocked for 1 sec or until they returned to the elevated starting platform. Thereafter, one nonshock trial per day was given for 21 days. Under the "1 sec shock" procedure, response latencies were influenced by the type of prior manipulation and the age at which it was experienced, with animals shocked during the postweaning period showing the longest latencies. Under the "variable shock" procedure, all previously manipulated groups had longer latencies than the controls.

Several studies have reported that early life experiences significantly influence the learning process, especially avoidance behavior, at maturity. Most often it has been found that handling facilitates the acquisition of avoidance responses, although there are discrepancies in the data which may be attributable to procedural as well as strain differences (Ader, 1965; Denenberg \& Karas, 1960; Denenberg \& Smith, 1963; King \& Eleftheriou, 1959; Levine, 1956; Levine \& Wetzel, 1963). Extinction of avoidance behavior has not received comparable attention, nor has it been conclusively established that the observed effects are the result of early as distinguished from previous experience. In the present study we investigated the effects of handling and electric shock stimulation experienced before and after weaning on the extinction of an avoidance response conditioned in one trial.

\section{Method}

Litters of Charles River (CD) rats were split within $24 \mathrm{~h}$ of birth and randomly divided into Handled $(\mathrm{H})$, Shocked (S), and Control (C) groups. Half the $H$ and $S$ groups were manipulated as previously described (Ader, 1965) during the first 21 days of life and half were manipulated during the 21 days immediately after weaning. The Ss were approximately 125 day old females randomly selected from this population and otherwise undisturbed until the beginning of avoidance training.

Animals were placed on a $2 \times 4$ in. platform situated in the center and elevated 2 in. above the floor of $\begin{array}{llllll} & 9 & \times & 8 & \times & 8\end{array}$ in. Plexiglas chamber. The time required to descend from the platform to the grid floor with three paws was recorded. Animals received five training trials per day with an intertrial interval of 2 min. On the day after an animal left the platform in 5 sec or less on three consecutive trials (a criterion usually achieved within the first five trials), it was returned to the apparatus and upon descending from the platform (with a latency $\leq 5 \mathrm{sec}$ ) was subjected to electric shock (1.0 $\mathrm{mA})$. In one experiment a single 1 sec shock was administered, and, in a second (variable shock) experiment, shock was administered continuously until the animal returned to the platform. Thereafter, no electric shock was applied in either procedure and each animal received one trial per day for 21 days. Animals were returned to their home cages upon descending from the platform or after a latency of 30 sec.

\section{Results}

The rates at which the differentially manipulated animals reached the preshock criterion did not differ in either experiment. Significant differences in extinction were observed, and these data are shown in Fig. 1.

The 1 sec shock and variable shock experiments were analyzed separately. Also, since the unmanipulated control animals could not be dichotomized on an "age at manipulation" continuum, separate analyses were used to compare the performance of $\mathrm{H}$ and $S$ groups before analysis of any of the manipulated groups relative to the controls.

Under the 1 sec shock procedure, $S$ animals had longer latencies than $H$ animals $(F=15.49, d f=1 / 23$, $\mathrm{p}<.01)$. There was also a Group by Age by Trials interaction $(F=2.33, \mathrm{df}=6 / 138, \mathrm{p}<.05)$, there being little difference between the $H$ and $S$ groups manipulated before weaning relative to the difference between the $\mathrm{H}$ and $\mathrm{S}$ groups manipulated after weaning which increased over trials. In contrast to Group H, ani-

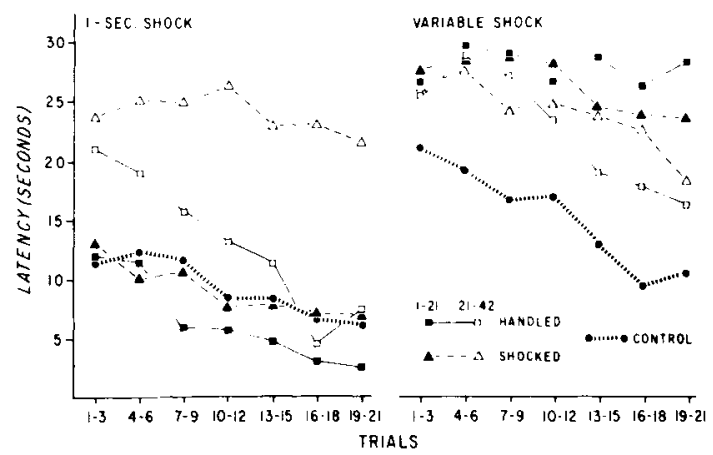

Fig. 1. Mean response latencies as a function of prior manipulations and the age at which they occurred. The Ns were as follows: $H(1-21)=8$, $\mathrm{H}(21-42)=6, \mathrm{~S}(1-21)=8, \mathrm{~S}(21-42)=5$, and $\mathrm{C}=13$ for the $1 \mathrm{sec}$ shock procedure, and $H(1-21)=6, H(21-42)=6, S(1-21)=5, S(21-42)=$ 6 , and $C=12$ for the variable shock procedure. 
mals shocked on Days 21-42 showed no decrease in latencies over 21 days. Only the longer latencies of the animals shocked on Days 21-42 were significantly different from the latencies of the controls $(F=15.90$, df $=1 / 16, p<.01$ ).

Although there were no differences in the number of trials to achieve the preshock criterion, there were differences in the amount of shock received on the single conditioning trial under the variable shock procedure. Animals manipulated on Days 21-42 of life received a mean of $40.8 \mathrm{sec}$ of shock before returning to the starting platform, whereas rats manipulated prior to weaning required $101.9 \mathrm{sec}$ $(F=13.87, d f=1 / 21, p<.01)$. Control animals received a mean of 93.8 sec of shock.

Under the variable shock procedure there were no differences in extinction between the $H$ and $S$ groups. Since age of manipulation did not affect latencies, these data were combined for the comparison of manipulated and control groups. This analysis indicated that the apparent decrease in latencies over trials was significant $(F=373.0, d f=6 / 192, p$ $<.01)$ and that the latencies of the manipulated groups were significantly greater than the latencies of the controls $(F=6.18, \mathrm{df}=2 / 32, \mathrm{p}<.01)$.

\section{Discussion}

A striking finding of this study was the relative difference in performance of the differentially treated groups in the two one trial avoidance procedures. It is apparent that the behavior of animals with different experiential histories is sensitive to what might appear to be minor procedural differences in the test situation and that procedural differences are a likely source of discrepant findings on the effects of early experiences on avoidance behavior.

One hypothesis which might explain the increased resistance to extinction displayed by the rats shocked on Days 21-42 of life under the 1 sec shock procedure is that such behavior reflects the relative recency with which these animals had been shocked previously. It is also possible that an experience with electric shock at maturity could re-establish responses previously conditioned during the immediate postweaning period to a greater extent than responses conditioned during the preweaning period. Such a hypothesis would be consistent with the data of Campbell \& Campbell (1962) which indicated that the retention of a learned fear response was greater in rats conditioned after rather than before weaning. Because handling is a part of the stimulus complex of the avoidance situa- tion, the high initial latencies of the rats handled on Days 21-42 are also consistent with this hypothesis.

On the single shock trial of the variable shock procedure the $\mathrm{H}$ and $\mathrm{S}$ groups manipulated postweaning returned to the starting platform faster than animals manipulated preweaning, thereby receiving less shock. The inference that this difference reflects some retention of previously learned behavior is consistent with our interpretation of the extinction data from the 1 sec shock procedure and, again, consistent with the hypothesis that such differences are a function of the greater retention of responses conditioned after as compared to before weaning. Despite the differences in the amount of shock received there were no differences in the extinction performance resulting from different prior experiences or the age at which they occurred. All manipulated groups showed a greater resistance to extinction than controls, suggesting that if prior conditioning plays a role it probably interacts with the intensity and/or duration of stimulation used in the avoidance conditioning.

Finally, these data showed that under certain experimental conditions, i.e., the variable shock procedure, the resistance to extinction of an avoidance response conditioned in a single trial is greater in both handled and shocked animals relative to previously unmanipulated controls. There was no evidence, however, that under these experimental conditions the observed differences were the result of early experiences per se.

\section{References}

ADER, R. Effects of early experience and differential housing on behavior and susceptibility to gastric erosions in the rat. J. comp. physiol. Psychol., 1965, 60, 233-238.

CAMPBELL, B. A., \& CAMPBELL, E. H. Retention and extinction of learned fear in infant and adult rats. J. comp. physiol. Psychol, 1962, $55,1-8$.

DENENBERG, V. H., \& KARAS, G. G. Interactive effects of age and duration of infantile experience on adult learning. Psychol Rep., 1960, 7, 313-322.

DENENBERG, V. H., \& SMITH, S. A. Effects of infantile stimulation and age upon behavior. J. comp. physiol. Psychol., 1963, 56, 307-312.

KING, J. A., \& ELEFTHERIOU, B. E. Effects of early handling upon adult behavior in two subspecies of deermice, Peromyscus maniculatus. J. comp. physiol. Psychol., 1959, 52, 82-88.

LEVINE, S. A further study of infantile handling and adult avoidance learning. J. Pers., 1956, 25, 70-80.

LEVINE, S., \& WETZEL, A. Infantile experiences, strain differences, and avoidance learning. J. comp. physiol. Psychol., 1963, 56, 879-881. Note

1. This research was supported by USPHS Grants MH03655 and K3 MH6318 from the National Institute of Mental Health. 